\title{
Effect of semen collection method (artificial vagina $v s$. electroejaculation), extender and centrifugation on post-thaw sperm quality of Blanca-Celtibérica buck ejaculates
}

\author{
P. Jiménez-Rabadán a , M. Ramón ${ }^{\mathrm{a}}$, O. García-Álvarez ${ }^{\mathrm{b}}$, A. Maroto-Morales $^{\mathrm{b}}$, E. del Olmo ${ }^{\mathrm{b}}$, \\ M.D. Pérez-Guzmán ${ }^{\mathrm{a}}$, A. Bisbal ${ }^{\mathrm{b}}$, M.R. Fernández-Santos ${ }^{\mathrm{b}}$, J.J. Garde ${ }^{\mathrm{b}}$, A.J. Soler ${ }^{\mathrm{b}, *}$ \\ a Regional Center of Animal Selection and Reproduction (CERSYRA), JCCM, 13300 Valdepeñas, Spain \\ b Biology of Reproduction Group, National Wildlife Research Institute (IREC), CSIC-UCLM-JCCM, 02071 Albacete, Spain
}

\section{A R T I C L E I N F O}

\section{Article history:}

Received 25 January 2012

Received in revised form 4 April 2012

Accepted 11 April 2012

Available online xxx

\section{Keywords:}

Blanca-Celtibérica buck

Artificial vagina

Electroejaculation

Cryopreservation

Freezing extender

Breeding season

\begin{abstract}
A B S T R A C T
The aim of this study was to evaluate the effect of semen collection method (artificial vagina compared to electroejaculation), season in which the semen was collected (breeding season compared to non-breeding season), freezing extender (Biladyl ${ }^{\circledR}$, Andromed $^{\circledR}$ and skim milk based extender) and pre-treatment procedure (washing compared to non-washing) on post-thaw semen quality in buck. Ejaculates from seven bucks of the Blanca-Celtibérica breed were collected by artificial vagina and electroejaculation during the breeding (July to December) and non-breeding season (January to June). Samples were split in two aliquots and one of them was washed. Three freezing extenders were evaluated on washing and non-washing sperm samples. Ejaculates collected by artificial vagina had a greater sperm quality after thawing, with greater values $(P \leq 0.05)$ for SM (sperm motility), NAR (acrosome intact), YO-PRO-1-/PI- (intact spermatozoa), and Mitotracker+/YO-PRO-1 - (spermatozoa with active mitochondria) and lower \% DFI (DNA fragmentation index). Thawed sperm samples which were collected during the breeding season had greater values $(P \leq 0.05)$ for NAR, intact spermatozoa and spermatozoa with active mitochondria, than those semen samples obtained during the non-breeding season. Semen freezing with Biladyl ${ }^{\circledR}$ and Andromed ${ }^{\circledR}$ resulted in a greater sperm quality $(P \leq 0.05)$ after thawing in relation to milk-based extender. Washing procedure had no effect on sperm parameters assessed at thawing. Results from the present study suggest that the success of semen cryopreservation in BlancaCeltibérica goat depends on semen collection method and season, as well as on the extender used. Thus, the post-thaw sperm quality will be greater $(P \leq 0.05)$ when samples are collected by artificial vagina during the breeding season and when Biladyl ${ }^{\circledR}$ or Andromed ${ }^{\circledR}$ are used as freezing extenders.
\end{abstract}

(c) 2012 Elsevier B.V. All rights reserved.

\section{Introduction}

The Blanca-Celtibérica goat is an autochthonous breed from Spain considered as an endangered breed.

\footnotetext{
* Corresponding author at: ETSIA, Campus Universitario s/n, 02071 Albacete, Spain. Tel.: +34 967599 200x2552; fax: +34 967599238.

E-mail address: anajosefa.soler@uclm.es (A.J. Soler).
}

Endangered breeds must be preserved by conservation methods. One of the conservation procedures consists of the development of genetic resource banks, cryopreserving gametes and embryos, thus allowing the storage of genetic resources indefinitely (Watson and Holt, 2001).

The first step for the creation of a sperm cryobank is the use of an effective method for the collection of the ejaculates. For domestic males, the artificial vagina (AV) procedure is the preferred method (Leboeuf et al., 2000),

0378-4320/\$ - see front matter (c) 2012 Elsevier B.V. All rights reserved. http://dx.doi.org/10.1016/j.anireprosci.2012.04.005 
but this technique requires a previous training period (Wulster-Radcliffe et al., 2001). Another method of collection such as the electroejaculation (EE) involves an alternative when males are not trained to AV or for wild species, and may be a viable method of repeatedly collecting ejaculates from individual specimens without causing death (Santiago-Moreno et al., 2009). The latter method could be an adequate alternative to collect ejaculates in Blanca-Celtibérica bucks because of there are few herds and they live under a extensive production system, being difficult to train them for AV. However, differences on sperm characteristics between ejaculates collected by AV and EE have been found, obtaining more desirable results when AV is used (Greyling and Gobbelaar, 1983). Besides, substantial differences in seminal plasma composition may exist between ejaculates obtained by AV and EE (Marco-Jiménez et al., 2008).

Sperm cryopreservation causes ultrastructural, biochemical and functional impairment to the spermatozoa (Aitken et al., 1998; Purdy, 2006; Watson, 2000). Egg yolk is a common component of sperm cryopreservation extender as a protector of the plasmatic and acrosomal membrane against temperature-related damaged (Purdy, 2006). The Tris-egg yolk-glucose and non-fat dried skimmed milk extenders are most commonly used for cryopreserving buck spermatozoa (Purdy, 2006). A specific problem in the preservation of goat semen has been its limited tolerance to the inclusion of egg yolk in the freezing medium. Seminal plasma has a detrimental effect on the viability of buck spermatozoa during cryopreservation when extender containing egg yolk is used (Sariözkan et al., 2010). This fact is due to seminal plasma contains egg yolk coagulating enzyme (EYCE), which hydrolyzes egg yolk lecithin into fatty acids and lysolecithin (Iritani and Nishikawa, 1961, 1963) which is highly detrimental to buck spermatozoa. Similarly, it has been identified the protein SBUIII from the goat bulbourethral gland which decreased survival of cooled or frozen sperm diluted in milk-based media. This protein could hydrolyze residual triglycerides in skim milk and produce fatty acids exhibiting toxic effects toward spermatozoa (Pellicer-Rubio et al., 1997). Currently, other extenders based on soybean have been used as an alternative to egg yolk in different species, obtaining for both extenders similar results (Aires et al., 2003; Forouzanfar et al., 2010).

In addition, many studies have reported that the washing procedure of goat semen for removing the seminal plasma from ejaculate is necessary to increase motility, membrane integrity, and fertility after freeze-thaw procedure (Kozdrowski et al., 2007; Machado and Simplicio, 1995). However, other studies have demonstrated that there was no effect of seminal plasma removing on postthaw sperm quality (Cabrera et al., 2005; Daskin and Tekin, 1996).

Finally, significant seasonal variation in the semen quality of small ruminants living at high or mid-levels altitudes have been demonstrated (Ritar, 1993; Roca et al., 1992) and the chemical composition and volume of the ejaculate may be different depending of season (Maxwell et al., 2007).

With this background, we have evaluated in BlancaCeltiberica bucks the effects of the collection method
(AV compared to EE), season in which the semen was collected (breeding season compared to non-breeding season), freezing extender (Biladyl ${ }^{\circledR}$, Andromed ${ }^{\circledR}$ and a skim milk-based extender) and pre-treatment procedure (washing compared to non-washing), on sperm quality after cryopreservation.

\section{Materials and methods}

\subsection{Animals and reagents}

All animal procedures were performed in accordance with Spanish Animal Protection Regulation, RD $1201 / 2005$, which conforms to European Union Regulation 2010/63. Seven males of Blanca-Celtibérica goat breed (age $>1.5$ years) were used. Males were maintained and managed at the Regional Center of Animal Selection and Reproduction (CERSYRA) located in Valdepeñas (Spain). The thawing procedure was conducted at laboratories from Group of Biology of Reproduction in Albacete (Spain).

Chemicals were of reagent grade and were purchased from Sigma (Madrid, Spain). Biladyl ${ }^{\circledR}$ and Andromed ${ }^{\circledR}$ were purchased from Minitüb (Tiefenbach, Alemania). Fluorescence probes were purchased from Invitrogen (Barcelona, Spain), except for propidium iodide (PI) which was purchased from Sigma. Chromatographically purified acridine orange was purchased from Polysciences Inc. (Warrington, PA, USA).

\subsection{Semen collection}

For each male, the collection of ejaculates was performed first using artificial vagina (AV) and later by electroejaculation (EE), both on the same day. Males were trained to conduct collections by AV. Ejaculates were routinely collected once per week. The procedure of EE was carried out using the protocol described by Garde et al. (2003). Males were sedated with xylacine $(0.2 \mathrm{mg} / \mathrm{kg}$ Rompun ${ }^{\circledR} 2 \%$ i.m.; Bayer S.A., Barcelona, Spain), then the rectum was cleaned of faeces and the prepucial area was shaved and washed with physiologic saline serum. For EE, we used a three electrode probe connected to a power source that allowed voltage and amperage control (P.T. Electronics, Boring, OR, USA). Probe diameter, probe length and electrode length was $3.2,35.0$ and $6.6 \mathrm{~cm}$, respectively. The EE regime consisted of consecutive series of 5-s pulses of similar voltage, each separated by 5 -s break. Each series consisted of a total of four pulses. The initial voltage was $1 \mathrm{~V}$ and was increased in each series until a maximum of $5 \mathrm{~V}$. Two ejaculates per buck and collection method were obtained during the breeding (July to December) and nonbreeding season (January to June), on a weekly basis.

\subsection{Evaluation of ejaculates}

Immediately after the collection of ejaculates, volume, sperm concentration, wave motion, subjective sperm motility (SM) and the percentage of spermatozoa with intact acrosomes (NAR) were determined. The volume of the ejaculates was measured in a conical graduated tube. Sperm concentration was calculated using 
a spectrophotometer. Spermatozoa total number (STN) was calculated with the volume and concentration (volume $\times$ concentration). Wave motion was assessed from fresh non-diluted semen and it was scored on a scale of $0-5$ being 0 : no movement and 5: strong wave movement. The percentage of motile spermatozoa was estimated from semen diluted $(1: 200)$ in a phosphate buffer saline (PBS) and evaluated subjectively using a phase-contrast microscope $(100 \times)$ in samples previously incubated for $5 \mathrm{~min}$ at $37^{\circ} \mathrm{C}$. Samples fixed in buffered $2 \%$ glutaraldehyde solution were used to assess NAR by observing spermatozoa using phase-contrast microscopy $(400 \times)$.

\subsection{Semen cryopreservation}

Semen from each male was aliquoted and used to conduct the different studies. One aliquot was washed with PBS (1:9) at $1200 \times \mathrm{g}$ for $10 \mathrm{~min}$ at room temperature and seminal plasma was removed. After that, washing and nonwashing sperm samples were split in three aliquots and diluted with three different extenders: two commercial extenders, Biladyl ${ }^{\circledR}$ (20\% egg yolk, using clarified egg yolk, and $7 \%$ glycerol) and Andromed ${ }^{\circledR}$ (soybean-based extender with 7\% glycerol) and a skim milk-based extender (7\% glycerol) prepared as described by Corteel (1974).

Semen dilution was performed by the two-step dilution method for Biladyl ${ }^{\circledR}$ and skim milk-based extender. First, non-glycerolated fraction was added at $30^{\circ} \mathrm{C}$ and the diluted semen was cooled to $5^{\circ} \mathrm{C}$ for $2 \mathrm{~h}$. Then, it was further diluted $(\mathrm{v}: \mathrm{v})$ with fraction containing glycerol. The diluted sperm samples were then held at $5^{\circ} \mathrm{C}$ for $2 \mathrm{~h}$ more before freezing (total refrigeration time at $5^{\circ} \mathrm{C}$ was $4 \mathrm{~h}$ ). For Andromed ${ }^{\circledR}$, samples were diluted in only one step at $30^{\circ} \mathrm{C}$ and then cooled to $5^{\circ} \mathrm{C}$ for $4 \mathrm{~h}$. At the end of this time, the diluted semen was loaded into $0.25 \mathrm{~mL}$ plastic straws and frozen. Straws were frozen over nitrogen vapours for $10 \mathrm{~min}, 4 \mathrm{~cm}$ above the nitrogen level, plunged and stored in liquid nitrogen. Sperm samples were frozen to a final concentration of $140-200 \times 10^{6}$ spermatozoa $/ \mathrm{mL}$.

\subsection{Thawed sperm evaluation}

Thawing was performed by dropping the straws in a water bath at $37^{\circ} \mathrm{C}$ for $30 \mathrm{~s}$ and pouring the semen in dry tubes and incubated for $5 \mathrm{~min}$ at the same temperature. For each male, season, method of semen collection, washing or non-washing process and freezing extender, one straw was thawed and analyzed.

Frozen-thawed spermatozoa were evaluated for SM and NAR, similar than for fresh semen. Motility was also evaluated by Computer Assisted Semen Analysis (CASA) using the Sperm Class Analyzer software $\left(\mathrm{SCA}^{\circledR}\right.$ 2002, Microptic, Barcelona, Spain). Sperm samples were diluted $(1: 1)$ with TALP-HEPES medium ( $87 \mathrm{mM} \mathrm{NaCl}, 3.1 \mathrm{mM} \mathrm{KCl}, 2 \mathrm{mM}$ $\mathrm{CaCl}_{2}, 0.4 \mathrm{mM} \mathrm{MgCl}_{2}, 0.3 \mathrm{mM} \mathrm{NaH} \mathrm{PO}_{4}, 40 \mathrm{mM}$ HEPES, $21.6 \mathrm{mM}$ sodium lactate, $1 \mathrm{mM}$ sodium pyruvate, $50 \mu \mathrm{g} / \mathrm{mL}$ kanamycin, $10 \mu \mathrm{g} / \mathrm{mL}$ phenol red, and $6 \mathrm{mg} / \mathrm{mL}$ bovine serum albumin (BSA) ( $\mathrm{pH} 7.5)$ ) and $5 \mu \mathrm{L}$ were put on a Makler chamber recording the characteristics of sperm motility. The following motility parameters were assessed: velocity according to the straight path (VSL, $\mu \mathrm{m} / \mathrm{s}$ ), amplitude of lateral head displacement (ALH, $\mu \mathrm{m})$ and linearity index (LIN, \%).

Also, aliquots of thawed semen were used to conduct flow cytometry analysis. We assessed the membrane stability with YO-PRO-1, the mitochondrial membrane potential with Mitotracker Deep Red and the viability with propidium iodide (PI) (Martínez-Pastor et al., 2008). A staining solution using TALP-HEPES was prepared by adding $50 \mathrm{nM}$ YO-PRO-1 (stock: $100 \mu \mathrm{M}$ in DMSO) and $15 \mu \mathrm{M}$ propidium iodide (stock: $7.5 \mathrm{mM}$ in Milli-Q water). We diluted $20 \mu \mathrm{L}$ of sample in $0.5 \mathrm{~mL}$ of staining solution in polypropylene tubes for flow cytometry. The tubes were allowed to rest for $15 \mathrm{~min}$ in the dark. Mitochondrial membrane potential of the samples were evaluated with $0.1 \mu \mathrm{M}$ YO-PRO-1 and $100 \mathrm{nM}$ Mitotracker Deep Red solution (stock: $1 \mathrm{mM}$ in DMSO) in TALP-HEPES. Mitotracker Deep Red is a far red-fluorescent dye (abs/em $\sim 640 / 662 \mathrm{~nm}$ ) which stains mitochondria in live cells and its accumulation is dependent upon membrane potential. Sperm samples were diluted to $10^{6}$ spermatozoa $/ \mathrm{mL}$, and $300 \mu \mathrm{L}$ were transferred to a polypropylene tube and left in the dark for $30 \mathrm{~min}$. After incubation times, sperm samples were analyzed using a Cytomics FC500 flow cytometer (Beckman coulter Inc. USA).

YO-PRO-1-/PI- spermatozoa were considered as intact spermatozoa (indicating live spermatozoa with intact plasmalemma), YO-PRO-1+/PI- as apoptotic spermatozoa (indicating live spermatozoa with altered plasmalemma) and Mitotracker+/YO-PRO-1- as viable spermatozoa with active mitochondria, as described by García-Álvarez et al. (2010).

Chromatin stability was assessed by using the SCSA ${ }^{\circledR}$ (Sperm Chromatin Structure Assay) technique (SCSA ${ }^{\circledR}$ Diagnostics Inc., Brookings, SD, USA) (Evenson and Jost, 2000). This technique is based in the susceptibility of the sperm DNA to acid-induced denaturation in situ and the metachromatic staining Acridine Orange (AO). This stain fluoresces green when combined with double-stranded DNA, and red when combined with single-stranded DNA (denaturated). Thawed spermatozoa were diluted with TNE buffer to $2 \times 10^{6}$ cells $/ \mathrm{mL}$. Samples were flash frozen in $\mathrm{LN}_{2}$ and stored at $-80^{\circ} \mathrm{C}$ until analysis. We calculated the DNA fragmentation Index (DFI) for each spermatozoon as the ratio of red fluorescence respect to total fluorescence (red + green). High values of DFI, indicates chromatin abnormalities. We calculated \% DFI, as the percentage of spermatozoa with DFI $>25$.

\subsection{Statistical analysis}

The R statistical environmental ( $\mathrm{R}$ Development Core Team, 2010) was used. Numeric results are expressed as the mean \pm standard error of the mean (SEM). Data were considered statistically significant when $P \leq 0.05$.

For the analysis, a mixed effects model with males as random effect was conducted. Effects of the method of collection (AV compared to EE) and season (breeding compared to non-breeding) on the quality of the ejaculates were studied. Differences on sperm quality after thawing between collection methods (AV compared to EE), seasons (breeding season compared to non-breeding 
Table 1

Effects of method of collection and season on the characteristics of ejaculates of the Blanca-Celtibérica bucks $(n=7)$.

\begin{tabular}{|c|c|c|c|c|c|}
\hline & \multicolumn{5}{|c|}{ Ejaculate characteristics } \\
\hline & Volume (mL) & $\begin{array}{l}\text { Concentration }(\times \\
\left.10^{6} \text { spermatozoa } / \mathrm{mL}\right)\end{array}$ & STN $\left(\times 10^{6}\right.$ spermatozoa $)$ & SM (\%) & NAR (\%) \\
\hline \multicolumn{6}{|l|}{ Collection method } \\
\hline AV & $1.1 \pm 0.2^{\mathrm{b}}$ & $2487.2 \pm 474.4^{\mathrm{a}}$ & $2498.0 \pm 474.4$ & $82.2 \pm 1.7$ & $88.2 \pm 1.3$ \\
\hline EE & $2.0 \pm 0.3^{\mathrm{a}}$ & $1163.0 \pm 274.2^{\mathrm{b}}$ & $2055.5 \pm 493.3$ & $84.5 \pm 1.7$ & $89.6 \pm 1.3$ \\
\hline \multicolumn{6}{|l|}{ Season } \\
\hline Breeding & $1.2 \pm 0.1$ & $2024.0 \pm 154.1$ & $2334.0 \pm 257.5$ & $76.8 \pm 1.8^{\mathrm{b}}$ & $93.4 \pm 0.8$ \\
\hline Non-breeding & $1.7 \pm 0.2$ & $2328.0 \pm 230.1$ & $2868.0 \pm 290.4$ & $86.9 \pm 1.0^{\mathrm{a}}$ & $95.2 \pm 0.8$ \\
\hline
\end{tabular}

Data are means \pm SEM. For each factor, different superscripts within a column differ $(P \leq 0.05)$. AV: artificial vagina; EE: electroejaculation; STN: total number of spermatozoa; SM: sperm motility; NAR: percentage of spermatozoa with intact acrosome.

season), freezing extenders (Biladyl ${ }^{\circledR}$, Andromed ${ }^{\circledR}$ and skim milk-based extender) and pre-treatments before freezing (washing compared to non-washing), together with the analysis of interactions: season $\times$ pre-treatment, collection method $\times$ season, collection method $\times$ freezing extender, collection method $\times$ pre-treatment, freezing extender $\times$ pre-treatment were evaluated. When interactions resulted no significant, they were removed from the analysis. Multiple comparisons analyses were carried out using the Bonferroni adjustment.

\section{Results}

The method of collection influenced $(P \leq 0.05)$ the volume and sperm concentration of ejaculates, showing those collected by AV the lesser volume and greatest sperm concentration (Table 1). At thawing, those ejaculates collected by AV had greater values $(P \leq 0.05)$ for SM and NAR, and no significant differences were found between both methods of collection for any motility parameter evaluated by CASA (Table 2). Ejaculates collected by AV also had greater values $(P \leq 0.05)$ for the percentage of intact spermatozoa and the percentage of spermatozoa with active mitochondria (Table 3). However, \% DFI was lower for sperm samples collected by AV in relation to those collected by EE.
On fresh semen, the season of collection had an effect on the percentage of motile spermatozoa, with greater values $(P \leq 0.05)$ on the non-breeding season (Table 1$)$. After thawing, the season influenced the NAR and LIN values $(P \leq 0.05)$, showing those ejaculates collected during breeding season greater percentages of NAR and lesser values of LIN (Table 2). Moreover, the percentages of intact spermatozoa and spermatozoa with active mitochondria assessed by means of flow cytometry were greater $(P \leq 0.05)$ when ejaculates were obtained during this breeding season (Table 3).

Regarding to the extender used for cryopreservation, semen samples diluted with Biladyl ${ }^{\circledR}$ or Andromed $^{\circledR}$ showed similar results on the quality of thawed semen. Thus, these samples had greater values $(P \leq 0.05)$ for the percentage of motile spermatozoa assessed subjectively, NAR, ALH, and the percentage of intact spermatozoa and spermatozoa with active mitochondria than for those samples diluted with skim milk-based extender (Tables 2 and 3). The latter samples had greater values $(P \leq 0.05)$ for the VSL and the LIN parameters.

Washing of sperm samples before diluting with freezing extenders did not influence $(P \geq 0.05)$ on sperm quality after thawing (Tables 2 and 3 ).

The interaction, season $\times$ pre-treatment was significant for SM, VSL and LIN (Fig. 1). Thus, the washing procedure

Table 2

Effects of method of collection, season, freezing extender and pre-treatment on subjective sperm motility, acrosomal integrity and motility evaluated by CASA of thawed semen on the Blanca-Celtibérica bucks $(n=7)$.

\begin{tabular}{|c|c|c|c|c|c|}
\hline & \multicolumn{5}{|c|}{ Sperm parameters } \\
\hline & SM (\%) & NAR (\%) & $\operatorname{VSL}(\mu \mathrm{m} / \mathrm{s})$ & LIN (\%) & $\mathrm{ALH}(\mu \mathrm{m})$ \\
\hline \multicolumn{6}{|l|}{ Collection method } \\
\hline AV & $43.4 \pm 3.9^{a}$ & $65.1 \pm 4.0^{\mathrm{a}}$ & $58.0 \pm 2.2$ & $55.4 \pm 1.3$ & $2.6 \pm 0.1$ \\
\hline $\mathrm{EE}$ & $24.5 \pm 4.2^{\mathrm{b}}$ & $56.4 \pm 4.4^{\mathrm{b}}$ & $57.1 \pm 3.0$ & $56.9 \pm 1.6$ & $2.4 \pm 0.1$ \\
\hline \multicolumn{6}{|l|}{ Season } \\
\hline Breeding & $34.6 \pm 4.1$ & $86.0 \pm 4.3^{\mathrm{a}}$ & $59.6 \pm 2.7$ & $54.5 \pm 1.5^{\mathrm{b}}$ & $2.6 \pm 0.1$ \\
\hline Non-breeding & $33.3 \pm 4.1$ & $35.6 \pm 4.3^{b}$ & $55.4 \pm 2.6$ & $57.9 \pm 1.5^{\mathrm{a}}$ & $2.4 \pm 0.1$ \\
\hline \multicolumn{6}{|c|}{ Freezing extender } \\
\hline Biladyl ${ }^{\circledR}$ & $45.3 \pm 4.3^{\mathrm{a}}$ & $61.3 \pm 4.5^{\mathrm{ab}}$ & $54.8 \pm 2.6^{\mathrm{b}}$ & $55.4 \pm 1.5^{\mathrm{b}}$ & $2.5 \pm 0.1^{\mathrm{a}}$ \\
\hline Andromed $^{\circledR}$ & $38.8 \pm 4.4^{\mathrm{a}}$ & $67.6 \pm 4.4^{\mathrm{a}}$ & $52.1 \pm 2.8^{\mathrm{b}}$ & $52.3 \pm 1.6^{\mathrm{b}}$ & $2.8 \pm 0.1^{\mathrm{a}}$ \\
\hline Skim milk & $17.7 \pm 4.4^{b}$ & $53.5 \pm 4.4^{b}$ & $65.6 \pm 3.3^{a}$ & $60.9 \pm 1.8^{a}$ & $2.2 \pm 0.1^{\mathrm{b}}$ \\
\hline \multicolumn{6}{|l|}{ Pre-treatment } \\
\hline Washing & $35.7 \pm 4.1$ & $58.9 \pm 4.2$ & $60.2 \pm 2.6$ & $56.5 \pm 1.5$ & $2.6 \pm 0.1$ \\
\hline Non-washing & $32.1 \pm 3.9$ & $62.6 \pm 4.2$ & $54.8 \pm 2.5$ & $55.9 \pm 1.4$ & $2.4 \pm 0.1$ \\
\hline
\end{tabular}

Data are means \pm SEM. For each factor, different superscripts within a column differ $(P \leq 0.05)$. AV: artificial vagina; EE: electroejaculation; SM: sperm motility; NAR: percentage of spermatozoa with intact acrosome; VSL: velocity according to the straight path; LIN: linearity index; ALH: amplitude of lateral head displacement. 
Table 3

Effects of method of collection, season, freezing extender and pre-treatment on post-thaw membrane integrity and DNA fragmentation index evaluated by flow cytometry of thawed semen on the Blanca-Celtibérica bucks $(n=7)$.

\begin{tabular}{|c|c|c|c|c|}
\hline & \multicolumn{4}{|l|}{ Sperm parameters } \\
\hline & YO-PRO-1-/PI- (\%) & YO-PRO-1+/PI- (\%) & Mitotracker+/YO-PRO-1- (\%) & $\%$ DFI \\
\hline \multicolumn{5}{|c|}{ Semen collection method } \\
\hline AV & $22.4 \pm 2.7^{a}$ & $8.8 \pm 0.9^{a}$ & $20.0 \pm 2.7^{a}$ & $3.2 \pm 0.5^{\mathrm{b}}$ \\
\hline $\mathrm{EE}$ & $14.9 \pm 2.8^{\mathrm{b}}$ & $4.4 \pm 0.9^{b}$ & $9.6 \pm 2.8^{\mathrm{b}}$ & $6.1 \pm 0.6^{a}$ \\
\hline \multicolumn{5}{|l|}{ Season } \\
\hline Breeding & $23.0 \pm 2.8^{\mathrm{a}}$ & $4.4 \pm 0.9^{b}$ & $19.0 \pm 2.8^{\mathrm{a}}$ & $4.8 \pm 0.6$ \\
\hline Non-breeding & $14.3 \pm 2.7^{\mathrm{b}}$ & $8.9 \pm 0.9^{\mathrm{a}}$ & $10.6 \pm 2.8^{\mathrm{b}}$ & $4.5 \pm 0.6$ \\
\hline \multicolumn{5}{|l|}{ Freezing extender } \\
\hline Biladyl $^{\circledR}$ & $25.6 \pm 2.8^{\mathrm{a}}$ & $6.2 \pm 0.9^{\mathrm{b}}$ & $20.0 \pm 2.8^{\mathrm{a}}$ & $4.7 \pm 0.6$ \\
\hline Andromed $^{\circledR}$ & $20.2 \pm 2.8^{\mathrm{b}}$ & $8.4 \pm 1.0^{\mathrm{a}}$ & $16.0 \pm 2.9^{\mathrm{a}}$ & $3.8 \pm 0.6$ \\
\hline Skim milk & $10.1 \pm 2.8^{\mathrm{c}}$ & $5.2 \pm 0.9^{b}$ & $8.4 \pm 2.9^{b}$ & $5.5 \pm 0.7$ \\
\hline \multicolumn{5}{|l|}{ Pre-treatment } \\
\hline Washing & $17.3 \pm 2.7$ & $7.2 \pm 0.9$ & $13.5 \pm 2.8$ & $4.8 \pm 0.6$ \\
\hline Non-washing & $20.0 \pm 2.7$ & $6.1 \pm 0.9$ & $16.1 \pm 2.8$ & $4.5 \pm 0.5$ \\
\hline
\end{tabular}

Data are means \pm SEM. For each factor, different superscripts within a column differ $(P \leq 0.05)$. AV: artificial vagina; EE: electroejaculation; YO-PRO1-/PI-: live spermatozoa with intact plasmalemma; YO-PRO-1+/PI-: apoptotic spermatozoa; Mitotracker+/YO-PRO-1-: viable spermatozoa with active mitochondria; \% DFI: DNA fragmentation index.

before freezing improved these sperm parameters when the semen was collected during non-breeding season. No other interactions resulted significant for any of the sperm parameters studied.

\section{Discussion}

In the present research, effects of semen collection method, season in which the semen was collected, freezing extender and pre-treatment before cryopreservation, on post-thaw motility and membrane integrity evaluated by CASA and flow cytometry, respectively, were studied in Blanca-Celtibérica bucks.

Electroejaculation allows collect ejaculates in animals whose training for AV is difficult. However, this method could leads to different ejaculates from those obtained by physiological way and could influence on the response of spermatozoa to different procedures such as cryopreservation. Results from the present study showed that ejaculates obtained by EE had a greater volume and lesser concentration in relation to those collected by AV, while no significant differences were found for SM and NAR between both collection methods for fresh semen. These results are similar to those to reported by Memon et al. (1986) and Marco-Jiménez et al. $(2005,2008)$ in bucks and rams, respectively. A greater volume for the ejaculates collected by EE could be due to contribution of accessory sex glands because of electrical stimuli as suggested by Mattner and Voglmayr (1962). In general, no significant differences were observed on the characteristics of the ejaculates regardless of the season of collection. These results agree with Pérez and Mateos (1996) in Malagueña bucks. Only those ejaculates collected during the non-breeding season had a greater percentage of motile spermatozoa, although differences among seasons were low and in both seasons the percentage of motile spermatozoa was high.

After freezing, results from the present study indicated semen samples from ejaculates collected by AV had greater values for most assessed sperm parameters than those obtained by EE, except for \% DFI. These results agree with those reported by Quinn et al. (1968) where ram spermatozoa collected by AV were more resistant to cold shock than those obtained by EE. However, other studies provided evidence that sperm quality after freezing was greater for
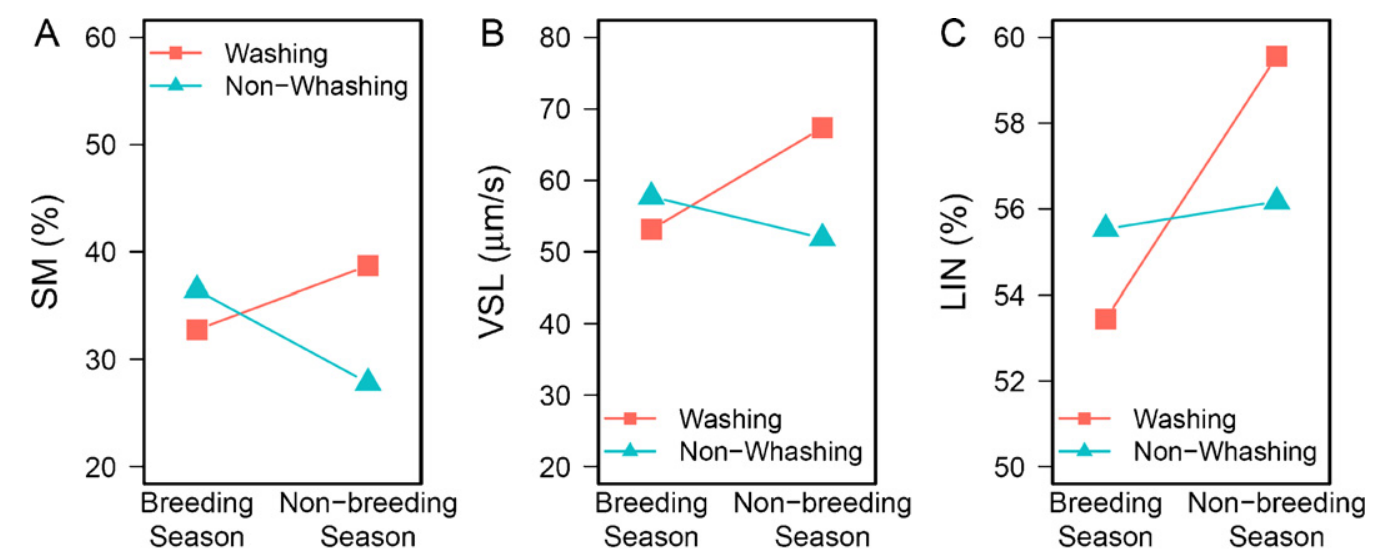

Fig. 1. Mean values for SM (sperm motility, \%), VSL (velocity according to the straight path, $\mu \mathrm{m} / \mathrm{s}$ ) and LIN (linearity index, \%) in thawed semen for the interaction between pre-treatment (washing $v s$. non-washing before dilution) and season in the Blanca-Celtibérica bucks ( $N=7$ ). 
those sperm samples obtained by EE in the same species (Marco-Jiménez et al., 2005). It is possible that the EE procedure changes the secretory function of one or more accessory glands so that could influence the amount of fluid produced and the chemical composition of the seminal plasma. This event could modify the survival to freezing of sperm samples obtained by this method. Marco-Jiménez et al. (2008) showed that seminal plasma from ram sperm samples obtained by EE was different for the $\mathrm{Na}^{+}$concentration in relation to $\mathrm{AV}$, with greater values of this ion for semen collected by EE. Also, in this previous study there were differences in the protein profile in samples obtained by both methods (Marco-Jiménez et al., 2008). Protein composition of seminal plasma has an important function for preventing the cold-shock sperm membrane damage (Barrios et al., 2005). In addition, in the seminal plasma there are substances that protecting to spermatozoa against to oxidative stress (Wat-sum et al., 2006). It is possible, that the concentration of these substances are altered in semen obtained by EE and it could be the reason for greater DNA damage in these samples, because of the relation between oxidative stress and sperm DNA damage (Aitken and Koppers, 2011).

Regarding to season of collection of the ejaculates, those samples which were obtained during the breeding season had more positive results for some parameters evaluated after thawing. These results agree with other studies conducted with other species of small ruminants (D'Alessandro and Martemucci, 2003). Coloma et al. (2011), showed that spermatozoa from Spanish Ibex collected during the winter (January to March) survived to freezing-thawing to a greater extent in relation to those collected in spring (April to June). The improved fertilisation potential of the frozen-thawed ram spermatozoa collected during the breeding season has been related to changes in total protein and protein composition of seminal plasma (Smith et al., 1999). This suggests that seminal plasma proteins may influence seasonal resistance of the spermatozoa to freeze-thaw damage. Thus, La Falci et al. (2002) showed that sperm samples supplemented with proteins from buck seminal plasma obtained during the non-breeding season led to deterioration of sperm quality, while other studies have demonstrated the positive effect on sperm quality after thawing when the semen was supplemented with proteins or seminal plasma collected during breeding season (Leahy et al., 2010).

The extender composition is crucial for spermatozoa protection against cryopreservation. In the present study, three extenders were compared: two commercial extenders, Biladyl $^{\circledR}$ (egg-yolk based extender) and Andromed ${ }^{\circledR}$ (soybean based extender), and a skim milk-based extender. Results of the present study indicated greater values for SM and NAR when the semen was cryopreserved with Biladyl ${ }^{\circledR}$ or Andromed ${ }^{\circledR}$. These results are consistent with those obtained by Sariözkan et al. (2010) who found similar values for SM and NAR in sperm samples cryopreserved with Triladyl $^{\circledR}$ (egg-yolk based extender) or Bioxcell ${ }^{\circledR}$ (soybean based extender). Also, Chauhan and Anand (1990) found that semen from bucks frozen with a Tris-egg yolk based extender had greater values of sperm quality in relation to that frozen with a skim milk-egg yolk based extender. In relation to sperm parameters evaluated by flow cytometry in the present study, lower values of intact spermatozoa and spermatozoa with active mitochondria were found in samples cryopreserved in milk-based extender in relation to that cryopreserved with Biladyl ${ }^{\circledR}$ or Andromed ${ }^{\circledR}$ with the greatest value for intact spermatozoa for the Biladyl ${ }^{\circledR}$. Similar results were reported by Chauhan and Anand (1990) when the viability was subjectively evaluated in samples frozen in egg yolk and skim milk-based extenders. However, in our study there were greater values for VSL and LIN in sperm samples cryopreserved in skim milk-based extender. Dorado et al. (2007) found greater values for objective motility parameters in samples frozen in an eggyolk based extender in relation to a milk-based extender, except for LIN which had a greater value in a milk based extender as was found in the present study. Results from our study could be due to the lesser viscosity of the skim milk-based extender, which could offers less resistance to the movement of spermatozoa. Viscosity in the medium surrounding the spermatozoa affects the pattern of sperm motion (Rikmenspoel, 1984).

In the present study there were not differences for DNA stability between the three extenders used. However, in other species such as cattle, an egg-yolk based extender offered more protection against sperm DNA damage in relation to a skim milk based extender (Waterhouse et al., 2010).

Results from the present study, therefore, provide evidence that sperm quality was affected less when buck ejaculates were cryopreserved with an extender with egg yolk in relation to soybean or skim milk-based extenders. It is possible, that the detrimental effect of the egg yolk based extender was less because, clarified egg yolk was used instead of whole egg yolk. The procedure of centrifugation used for obtaining clarified egg yolk might remove substances harmful for spermatozoa frozen in egg yolk based extenders. Another possibility is that phospholipids of egg yolk were not hydrolyzed by enzymes of seminal plasma (phospholipase $\mathrm{A}_{2}$ and lysophospholipase), as has been shown by Chauhan and Anand (1990).

In our study, effects of seminal plasma removal (washing) on sperm parameters at thawing was also studied. In several previous studies, it has been suggested the washing procedure of goat semen is a beneficial process because it avoids that EYCE and protein SBUIII acts (Kozdrowski et al., 2007; Machado and Simplicio, 1995). In the present study there were no differences between washing and nonwashing samples. Moreover, washing is a complex-time consuming process, and also causes some loss of spermatozoa (Ritar, 1993). Nevertheless, the positive effect of washing can depend on the season of the year and the freezing extender used (Cabrera et al., 2005; Sariözkan et al., 2010). We did not find no interaction between pre-treatment (washing or non-washing) and the freezing extender for all sperm parameters assessed, being independent the washing effect from the diluents of cryopreservation used. However, in the present study there was a significant interaction between pre-treatment and season for SM, VSL and LIN. Thus, values for these sperm parameters were greater when samples were washed in the non-breeding season. Cabrera et al. (2005) observed 
similar results, showing that samples collected during spring (non-breeding season) had greater cryosurvival when the washing procedure was performed and samples frozen during winter (breeding season) had greater cryosurvival when the washing procedure was not performed. Phospholipase activity is greater during nonbreeding season (Ritar and Salamon, 1991) and it is possible that the washing procedure removes proteins which have a detrimental activity.

In conclusion, results of the present study suggest that the success of the semen cryopreservation in BlancaCeltibérica goat depends on the semen collection method, breeding season in which the ejaculates are collected and extender used. Sperm quality after cryopreservation is greater when ejaculates are obtained by AV and are collected during the breeding season. Also, there are more desirable results for most sperm parameters assessed after thawing when Biladyl ${ }^{\circledR}$ or Andromed ${ }^{\circledR}$ are used as freezing extenders as compared to a skim milk-based extender, irrespective of semen collection method. Moreover, the washing procedure did not show any improvement on post-thawing sperm quality.

\section{Acknowledgements}

This research was supported by INIA (RZ2008-00009CO2). The authors thank AGRACE, their farmers and CERSYRA staff for their collaboration in the collection of the samples. Pilar Jiménez-Rabadán is recipient of scholarship from INIA. Manuel Ramón is supported by the DOC-INIA program (Ministry of Science and Innovation of Spain).

\section{References}

Aires, V.A., Hinsch, K.D., Mueller-Schloesser, F., Bogner, K., MuellerSchloesser, S., Hinsch, E., 2003. In vitro and in vivo comparison of egg yolk-based and soybean lecithin-based extenders for cryopreservation of bovine semen. Theriogenology 60, 269-279.

Aitken, R.J., Gordon, E., Harkiss, D., Twigg, J.P., Milne, P., Jennigs, Z., Irvine, D.S., 1998. Relative impact of oxidative stress on the functional competence and genomic integrity of human spermatozoa. Biol. Reprod. 59, 1037-1046.

Aitken, R.J., Koppers, A.J., 2011. Apoptosis and DNA damage in human spermatozoa. Asian J. Androl. 13, 36-42.

Barrios, B., Fernández-Juan, M., Muiño-Blanco, T., Cebrián-Pérez, J.A., 2005. Inmunocytochemical localization and biochemical characterization of two seminal plasma proteins that Project ram spermatozoa. J. Androl. 26, 539-549.

Cabrera, F., González, F., Batista, M., Calero, P., Medrano, A., Gracia, A., 2005. The effect of removal of seminal plasma, egg yolk level and season on sperm freezability of canary buck (Capra hircus). Reprod. Domest. Anim. 40, 191-195.

Chauhan, M.S., Anand, S.R., 1990. Effect of egg yolk lipids on the freezing goat semen. Theriogenology 34, 1003-1013.

Coloma, M.A., Toledano-Díaz, A., Castaño, C., Velázquez, R., Gómez-Brunet, A., López-Sebastian, A., Santiago-Moreno, J., 2011. Seasonal variation in reproductive physiological status in the Iberian Ibex (Capra pyrenaica) and its relationship with sperm freezability. Theriogenology 129, 56-66.

Corteel, J.M., 1974. Viabilité des espermatozoides de bouc conservés et congelés avec ou sans leur plasma seminal: effect du glucose. Ann. Biol. Anim. Biochim. Biophys. 14 (4-B), 741-745.

D'Alessandro, A.G., Martemucci, G., 2003. Evaluation of seasonal variations of semen freezability in Leccese ram. Anim. Reprod. Sci. 79, 93-102.

Daskin, A., Tekin, N., 1996. The effect of egg yolk on quality of frozen Angora goat semen. Turk. J. Vet. Anim. Sci. 20, 395-398.

Dorado, J., Rodríguez, I., Hidalgo, H., 2007. Cryopreservation of goat spermatozoa: comparison of two freezing extenders based on post-thaw sperm quality and fertility rates after artificial insemination. Theriogenology 68, 168-177.

Evenson, D.P., Jost, L., 2000. Sperm chromatin structure assay is useful for fertility assessment. Methods Cell Sci. 22, 169-189.

Forouzanfar, M., Sharafi, M., Hosseini, S.M., Ostadhosseini, S., Hajian, M. Hosseini, L., Abedi, P., Nili, N., Rahmani, H.R., Nasr-Estahani, M.H., 2010. In vitro comparison of egg yolk-based and soybean lecithinbased extenders for cryopreservation of ram semen. Theriogenology 73, 480-487.

García-Álvarez, O., Maroto-Morales, A., Ramón, M., del Olmo, E., Montoro, V., Dominguez-Rebolledo, A.E., Bisbal, A., Jiménez-Rabadán, P., PérezGuzmán, M.D., Soler, A.J., 2010. Analysis of selected sperm by density gradient centrifugation might aid in the estimation of in vivo fertility of thawed ram spermatozoa. Theriogenology 74, 979-988.

Garde, J.J., Soler, A.J., Cassinello, J., Crespo, C., Malo, A.F., Espeso, G., Gomendio, M., Roldan, E.M.S., 2003. Sperm cryopreservation in three species of endangered gazelles (Gazella cuvieri, G. dama mhorr, and G. dorcas neglecta). Biol. Reprod. 69, 602-611.

Greyling, J.P.C., Gobbelaar, J.A.N., 1983. Seasonal variation in semen quality of Boer and Angora goat rams using different collection techniques. S. Afr. J. Anim. Sci. 13, 250-252.

Iritani, A., Nishikawa, Y., 1961. Studies on the egg yolk coagulating factor in goat semen. II. Properties of the coagulating factor and influential condition for coagulation. In: Proceedings of the Silver Jubilee Lab Anim Husbandry, Kyoto University, pp. 97-104.

Iritani, A., Nishikawa, Y., 1963. Studies on the egg yolk coagulating factor in goat semen. III. Release of some acids accompanied by the coagulating phenomena. J. Anim. Reprod. 8, 109-112.

Kozdrowski, R., Dubiel, A., Bielas, W., Dzieciol, M., 2007. Two protocols of cryopreservation of goat semen with the use of computer-assisted semen analysis system. Acta Vet. Brno 76, 601-604.

La Falci, V.S.N., Tortorella, H., Rodrígues, J.L., Brandelli, A., 2002. Seasonal variation of goat seminal plasma proteins. Theriogenology 57 , 1035-1048.

Leahy, T., Marti, J.I., Evans, G., Maxwell, W.M.C., 2010. Seasonal variation in the protective effect of seminal plasma on frozen-thawed ram spermatozoa. Anim. Reprod. Sci. 119, 147-153.

Leboeuf, B., Restall, B., Salamon, S., 2000. Production and storage of goat semen for artificial insemination. Anim. Reprod. Sci. 62, 113-141.

Machado, R., Simplicio, A., 1995. Effects of two washing solutions on sperm survival of the bucks. In: Proceeding of the International Conference of Goats, vol. 2, Council of Agric. Res., New Delhi, pp. 1089-1109.

Marco-Jiménez, F., Puchades, S., Gadea, J., Vicente, J.S., Viudes-de-Castro, M.P., 2005. Effect of semen collection method on pre- and post-thaw Guirra ram spermatozoa. Theriogenology 64, 1756-1765.

Marco-Jiménez, F., Vicente, J.S., Viudes-de-Castro, M.P., 2008. Seminal plasma composition from ejaculates collected by artificial vagina and electroejaculation in Guirra ram. Reprod. Domest. Anim. 43, 403-408.

Martínez-Pastor, F., Fernández-Santos, M.R., del Olmo, E., DomínguezRebolledo, A.E., Esteso, M.C., Montoro, V., Garde, J.J., 2008. Mitochondrial activity and forward scatter vary in necrotic, apoptotic and membrane-intact spermatozoa subpopulations. Reprod. Fertil. Dev. 20, 547-556.

Mattner, P.E., Voglmayr, J.K., 1962. A comparison of ram semen collection by the artificial vagina and by electroejaculation. Aust. J. Exp. Agric. Anim. Husb. 2, 78-81.

Maxwell, W.M., de Graaf, S.P., Ghaoui, Rel-H., Evans, G., 2007. Seminal plasma effects on sperm handling and female fertility. Soc. Reprod. Fertil. Suppl. 64, 12-38.

Memon, M.A., Bretzlaff, K.N., Ott, R.S., 1986. Comparison of semen collection techniques in goats. Theriogenology 26, 823-827.

Pellicer-Rubio, M.T., Magallon, T., Combarnous, Y., 1997. Deterioration of goat sperm viability in milk extenders is due to a bulbourethral 60kilodalton glycoprotein with triglyceride lipase activity. Biol. Reprod. 57, 1023-1031.

Pérez, B., Mateos, E., 1996. Effect of photoperiod on semen production and quality in bucks of Verata and Malagueña breeds. Small Rumin. Res. $23,23-28$

Purdy, P.H., 2006. A review on goat sperm cryopreservation. Small Rumin. Res. 63, 215-225.

Quinn, P.J., Salamon, S., White, I.G., 1968. The effect of cold shock and deep-freezing on ram spermatozoa collected by electrical ejaculation and by an artificial vagina. Aust. J. Agric. Res. 19, 119-128.

R Development Core Team, 2010. R: A Language and Environment for Statistical Computing. R Foundation for Statistical Computing, Vienna, Austria, ISBN 3-900051-07-0, http://www.R-project.org.

Rikmenspoel, R., 1984. Movements and active movements of bull sperm flagella as a function of temperature and viscosity. J. Exp. Biol. 108, 205-230. 
Ritar, A.J., Salamon, S., 1991. Effects of month of collection, method of processing, concentration of egg yolk and duration of frozen storage on viability of Angora goat spermatozoa. Small Rumin. Res. 41, 29-37.

Ritar, A.J., 1993. Control of ovulation, storage of semen and artificial insemination of fibre-producing goats in Australia: a review. Aust. J. Exp. Agric. 33, 807-820.

Roca, J., Martínez, E., Sanchez-Valverde, M.A., Ruiz, S., Vazquez, J.M., 1992. Seasonal variations of semen quality in male goats: study of sperm abnormalities. Theriogenology 38, 115-125.

Santiago-Moreno, J., Coloma, M.A., Dorado, J., Pulido-Pastor, A., GómezGuillamon, F., Salas-Vega, R., Gómez-Brunet, A., López-Sebastián A., 2009. Cryopreservation of Spanish ibex (Capra pyrenaica) sperm obtained by electroejaculation outsider the rutting season. Theriogenology 71, 1253-1260.

Sariözkan, S., Bucak, M.N., Tuncer, P.B., Tasdemir, U., Kinet, H., Ulutas, P.A., 2010. Effects of different extenders and centrifugation/washing on post-thaw microscopic-oxidative stress parameters and fertilizing ability of Angora buck sperm. Theriogenology 73, 316-323.
Smith, J.F., Parr, J., Murray, G.R., McDonald, R.M., Lee, R.S.F., 1999. Seasonal changes in the protein content and composition of ram seminal plasma. In: Proceedings of the New Zealand Society of Animal Production, vol. 59, pp. 223-225.

Waterhouse, K.E., Gieldnes, A., Tverdal, A., De Angelis, P.M., Farstad, W., Haard, M., Kommisrud, E., 2010. Alterations of sperm DNA integrity during cryopreservation procedure and in vitro incubation of bull semen. Anim. Reprod. Sci. 117, 34-42.

Watson, P.F., 2000. The causes of reduced fertility with cryopreserved semen. Anim. Reprod. 60-61, 481-492.

Watson, P.F., Holt, W.V., 2001. Organizational issues concerning the establishment of a genetic resource bank. In: Watson, P.F., Holt, W.V. (Eds.), Cryobanking the Genetic Resource. Wildlife Conservation the Future? Taylor \& Francis, London, pp. 86-112.

Wat-sum, O., Chen, H., Chow, P.H., 2006. Male genital tract antioxidant enzymes-their ability to preserve sperm DNA integrity. Mol. Cell. Endocrinol. 205, 80-83.

Wulster-Radcliffe, M.C., Wiliams, M.A., Stellflug, J.N., Lewis, G.S., 2001. Technical note: artificial vagina vs. a vaginal collection vial for collecting semen from rams. J. Anim. Sci. 79, 2964-2967. 